\title{
The International Study on Career Choice in Psychiatry: a preliminary report
}

\author{
Dinesh Bhugra, on behalf OF the \\ Steering Group (Kitty FarooQ, \\ Greg Lydall, Amit Malik AND \\ Rob Howard) \\ Institute of Psychiatry, King's College London, \\ De Crespigny Park, London SE5 8AF, UK
}

As part of the WPA Action Plan 2008-2011 (1), it was agreed to explore reasons which put medical students off psychiatry. Indeed, over the past three decades, concerns have been raised about difficulties in recruiting medical students into psychiatry (2). It has been shown that poor recruitment is influenced by a number of factors which can be addressed readily (3).

Potential psychiatrists fall into three major groups: a) those who choose psychiatry as a speciality prior to joining medical school and stick with this choice (some would have gone into medicine to do psychiatry; this may be linked with direct or indirect exposure to mental illness or to mental health professionals); b) those who decide during medical school, who are likely to be influenced by teachers and quality of clinical attachment and experience; c) those who decide after qualification or change their minds after exposure to other specialities out of interest, for career prospects or work-life balance.

We explored these three sets of factors among final year medical students in 20 countries through selected medi- cal schools. Questionnaires were used (in e-mail or paper versions according to the respondents' preferred method of contact) to assess attitudes towards psychiatry (Attitudes Toward Psychiatry 18 items, ATP-18) and personality traits (International English Mini-Markers), along with questions on teaching methods and exposure to the subject.

A total of 2198 students responded. $4.5 \%$ of the sample planned to become psychiatrists, with a further $15 \%$ considering it as a possible career. Women were more likely to consider psychiatry than men. Key factors associated with choosing psychiatry were personal or family exposure to physical or mental illness. $2.7 \%$ of the sample had decided to be a psychiatrist before admission to medical school and three quarters maintained this choice by their final year.

The quality and quantity of teaching received was positively correlated with attitudes towards psychiatry. Special study courses, electives, research opportunities and exposure in psychiatry, and university psychiatry clubs were all significantly associated with choice of psychiatry. Clinical experience of seeing and participating in managing acute patients contributed positively too.

Career pathways need to be flexible, to encourage especially those who want a better work-life balance to choose psychiatry as a speciality. It is important that the WPA, in conjunction with national associations, set up and maintain an international electives network to expose interested students to clinical, research and policy options, and support student psychiatric clubs and associations. National associations and medical schools should work together to offer medical students attachments to work with researchers and clinicians. The WPA needs to set up an online resource centre to bring stakeholders in recruitment together.

Further work is required to explore differences within the same country across the various medical schools and to understand what influences decision making. It would be useful to repeat the study in a few years' time to explore if interventions put in place have borne fruit.

\section{References}

1. Maj M. Report on the implementation of the WPA Action Plan 2008-2011. World Psychiatry 2011;10:161-4.

2. Goldacre MJ, Laxton L, Lambert TW. Medical graduates' early career choices of specialty and their eventual specialty destinations: UK prospective cohort studies. BMJ 2010;341: c3199.

3. Eagle PF, Marcos LR. Factors in medical students' choice of psychiatry. Am J Psychiatry 1980;137:423-7.

DOI 10.1002/wps.20044

with the presidents of the societies and institutions in the regions. We are trying to identify subject areas and issues of great relevance to the profession and the communities. Moreover, the model emphasizes the development of educational networks with the participation of experts in different areas of psychiatry. 
Among the main recent activities are the educational seminar on bipolar disorder held in Lima, Peru in May 2012 (attended by about 90 psychiatrists from almost all Latin American countries); the educational programme on response to emergencies held in Bali, Indonesia in September 2012; the educational programme on preventive psychiatry held in Bilbao, Spain in September 2012; the educational symposium taking place in Prague, Czech Republic in October 2012, focusing on early career psychiatrists; the educational symposium held in Natal, Brazil in November 2012, on education and training in medical practice; the educational forum held in Buenos Aires, Argentina, in November 2012 on the identity of Latin America psychiatry; the educational seminar held in Athens, Greece in November 2012 on the multidisciplinary facets of psychiatry; the educational symposium taking place in $\mathrm{La}$ Asuncion, Paraguay in January 2013, on Latin American perspectives about addressing mental needs; the educational seminar on schizophrenia held in Cairo, Egypt in January 2013; and the educational symposium on fighting stigma and discrimination taking place in Guayaquil, Ecuador in February 2013.

The educational materials available on the WPA website (www.wpanet. org) include: the WPA e-learning programme, covering videos and slide sets of prominent scientific lectures from WPA meetings (1); the three sets of slides based on the WPA books dealing with the comorbidity of depression with diabetes, heart disease and cancer (2-4); the educational module on physical illness in patients with severe mental disorders $(5,6)$; the WPA guidance papers on implementation of community mental health care (7), how to combat stigmatization of psychiatry and psychiatrists (8), mental health care in migrants (9), and promotion of mental health in children of persons with severe mental disorders (10); the WPA template for undergraduate and postgraduate education in psychiatry and mental health; the recommendations for relationships of psychiatrists and psychiatric organizations with the pharmaceutical industry (11); the recommendations on best practices in working with service users and carers (12); the WPA/PTD educational programme on depressive disorders, and the WPA/ISSPD educational programme on personality disorders.

\section{References}

1. Kuey L. The characteristics, content, performance, and impact of the WPA website (www.wpanet.org). World Psychiatry 2013;12:85-6.

2. Katon W, Maj M, Sartorius N. Depression and diabetes. Chichester: Wiley, 2010.

3. Glassman A, Maj M, Sartorius N. Depression and heart disease. Chichester: Wiley, 2011.

4. Kissane DW, Maj M, Sartorius N. Depression and cancer. Chichester: Wiley, 2011.
5. De Hert M, Correll CU, Bobes J et al. Physical illness in patients with severe mental disorders. I. Prevalence, impact of medications and disparities in health care. World Psychiatry 2011;10:52-77.

6. De Hert M, Cohen D, Bobes J et al. Physical illness in patients with severe mental disorders. II. Barriers to care, monitoring and treatment guidelines, plus recommendations at the system and individual level. World Psychiatry 2011;10:138-51.

7. Thornicroft G, Alem A, Dos Santos RA et al. WPA guidance on steps, obstacles and mistakes to avoid in the implementation of community mental health care. World Psychiatry 2010;9:67-77.

8. Sartorius N, Gaebel W, Cleveland HR et al. WPA guidance on how to combat stigmatization of psychiatry and psychiatrists. World Psychiatry 2010;9:131-44.

9. Bhugra D, Gupta S, Bhui K et al. WPA guidance on mental health and mental health care in migrants. World Psychiatry 2011;10:2-10.

10. Brockington I, Chandra P, Dubowitz H et al. WPA guidance on the protection and promotion of mental health in children of persons with severe mental disorders. World Psychiatry 2011;10:93-102.

11. Appelbaum P, Arboleda-Florez J, Javed A et al. WPA recommendations for relationships of psychiatrists, health care organizations working in the psychiatric field and psychiatric associations with the pharmaceutical industry. World Psychiatry 2011;10:155-8.

12. Wallcraft J, Amering M, Freidin J et al. Partnerships for better mental health worldwide: WPA recommendations on best practices in working with service users and family carers. World Psychiatry 2011;10:229-37.

DOI 10.1002/wps.20047

\section{WPA scientific meetings}

\section{TaRek ОкASHa}

WPA Secretary for Scientific Meetings

Since my election as WPA Secretary for Meetings during the 14th World Congress of Psychiatry in September 2008, I have had the opportunity to work during the triennium 2008-2011 under the leadership of Prof. Mario Maj. During the triennium 2008-2011, the WPA scientific meetings were held in all the WPA four regions and in all the WPA 18 zones ((1)). The WPA held a total of 138 scientific meetings. Out of those meetings, 11 were WPA sponsored meetings (so called when the organizing committee takes responsibility for hosting a meeting of the WPA Executive Committee) and 127 were WPA co-sponsored meetings (so called when they are organized by
WPA Member Societies and other organizations or institutions whose goals are harmonious with those of the WPA) $((2,3))$. A major scientific impact was the number of mental health professionals (psychiatrists, psychologists, nurses, primary care physicians) reached by the WPA scientific meetings, making a total of 127,417 . The triennium ended with the 15th World Congress of Psychiatry, which was 